\title{
Organophosphate ester (OPEs) flame retardants and plasticizers in air and soil from a highly industrialized city in Turkey
}

\author{
Perihan Kurt-Karakus a ${ }^{a}$, Henry Alegria ${ }^{\mathrm{b}, *}$, Askin Birgul ${ }^{\mathrm{a}}$, Elif Gungormus ${ }^{\mathrm{c}}$, Liisa Jantunen ${ }^{\mathrm{d}}$

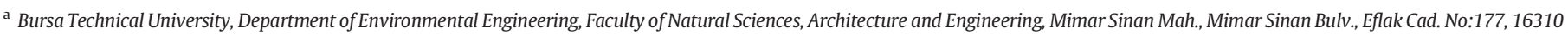 \\ Yildirım/Bursa/, Turkey \\ ${ }^{\mathrm{b}}$ University of South Florida St Petersburg, Department of Environmental Science, Policy E Geography, 140 7th Avenue South, St. Petersburg, FL 33701, USA \\ c Izmir Institute of Technology, Department of Chemical Engineering, Gülbahçe, Urla 35430, Izmir, Turkey \\ ${ }^{\mathrm{d}}$ Air Quality Processes Research Section, Environment and Climate Change Canada, 6248 8th Line, Egbert, Ontario, Canada
}

\section{H I G H L I G H T S}

- Organophosphate ester flame retardants and plasticizers (OPEs) were measured in air and soil in Bursa, Turkey.

- Seasonal air patterns differed between total and alkylated versus halogenated and aryl OPEs, with differences among sites.

- Annual air concentrations were dominated by alkylated OPEs with lower levels of halogenated and aryl OPEs at all 8 sites.

- OPE levels were similar to or higher than PBDE air levels reported for Turkey and other locations globally.

\section{A R T I C L E I N F O}

\section{Article history:}

Received 5 June 2017

Received in revised form 23 December 2017

Accepted 26 December 2017

Available online 30 December 2017

Editor: Kevin V. Thomas

\section{Keywords:}

Organophosphate ester flame retardants

Plasticizers

Turkey

Environment

Urban

Suburban

Rural

\section{G R A P H I C A L A B S T R A C T}

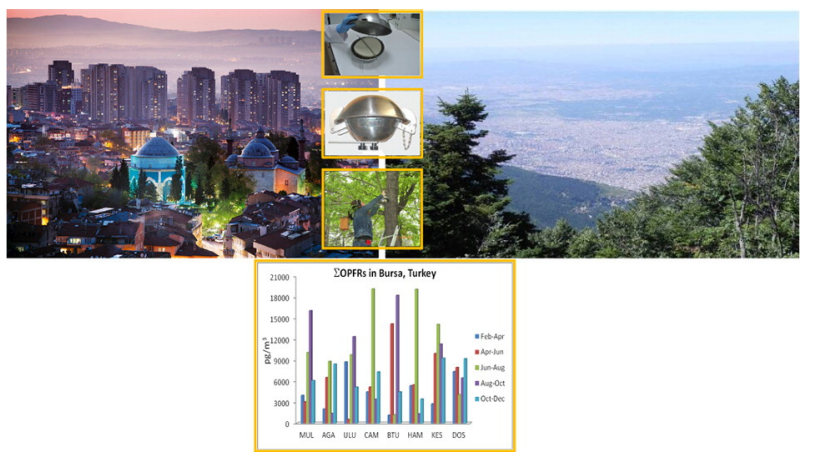

\section{A B S T R A C T}

Passive air samples were collected at eight sites in Bursa, Turkey during five sampling periods between FebruaryDecember 2014. Locations encompassed urban, suburban, industrial, rural and background environments. Soil samples $(n=8)$ were collected at each site during February 2014. Six OPEs were detected in samples: tris(2chloroethyl) phosphate (TCEP), tris(chloropropyl) phosphate (TCPP), triphenyl phosphate (TPHP), tris(2butoxyethyl) phosphate (TBOEP), tris(2-ethylhexyl) phosphate (TEHP), and tris(2-isopropylphenyl) phosphate (T2iPPP). Frequency of detection in air samples was TCPP and TPHP $(100 \%)>$ TBOEP $(88 \%)>$ TCEP $(85 \%)>$ TEHP (78\%) > T2iPPP (20\%). Total OPEs in air per site by sampling period (excluding non-detects) ranged from 529 to $19,139 \mathrm{pg} / \mathrm{m}^{3}$. In soil, total OPEs ranged from 38 to $468 \mathrm{ng} / \mathrm{g} \mathrm{dw}$. In air, alkylated OPEs dominated followed by halogenated and aryl OPEs. In air, annual mean concentrations were TBOEP $>$ TCPP $>$ TPHP $>$ T2iPPP $>$ TEHP $>$ TCEP. In soils, alkylated OPEs were dominant at six sites and chlorinated OPEs at two sites. A comparison of OPE profiles between air and soil suggests that soils may be partly a source of OPEs to air. Mean concentrations in air were not directly proportional to temperature, and there were differences between alkylated compared to halogenated and aryl OPEs. In air, total and alkylated OPEs levels were fairly uniform, whereas more variability was found for the halogenated and aryl compounds. The relative contribution to total OPEs decreases for alkylated OPEs and increases for halogenated OPEs in samples going from background to suburban to urban and industrial sites. Levels of individual OPEs were all positively correlated between air and soils. In air,

\footnotetext{
* Corresponding author.

E-mail address: halegria@usfsp.edu (H. Alegria).
} 
correlations between individual compounds were weak to moderate and were only statistically significant for TBOEP and TPHP. In soils, correlations were generally stronger and statistically significant only for TPHP and T2iPPP.

(c) 2017 Elsevier B.V. All rights reserved.

\section{Introduction}

Flame retardants are chemicals that are added to many consumer products such as plastics, electronics, textiles, foams for furniture, automobile interiors and many others. The most widely used flame retardants have been polybrominated diphenyl ethers (PBDEs) until commercial mixtures of these chemicals were banned, and then alternative chemicals including organophosphate flame retardants (OPEs) and non-PBDE brominated new flame retardants (NBFRs) became available as replacements.

OPEs are used as flame retardants and plasticizers in a variety of consumer and industrial products such as plastics, electronic equipment, furniture, textiles and building materials and plasticizers and antifoaming agent in various products such as lacquers, hydraulic fluids and floor polishes (Van der Veen and de Boer, 2012; Marklund et al., 2003, 2005; Reemtsma et al., 2008; Abdallah and Covaci, 2014). In 2013, the market volume of OPEs usage as flame retardant was approximately $620 \mathrm{kt}$, accounting for $30 \%$ of the global total (China Market Research Reports, 2016). Generally, halogenated OPEs are FRs (for example TCPP is added to spray foam insulation and TDCPP to polyurethane foam) whereas aryl and alkylated OPEs are plasticizers, although there are some compounds used for both (for example, TPhP is a plasticizer but is also a component of FireMaster 550).

OPEs were reported in river water, seawater and sediment (Tachikawa et al., 1975; Meijers and van der Leer, 1976; Sheldon and Hites, 1978) as early as 1970s. Although OPEs have been widely used for decades, after some studies in the 1980s indicated that these chemicals degrade quickly in the environment interest waned. Studies on environmental samples such as ambient air (Salamova et al., 2014a; Luo et al., 2016), biota (Muir et al., 1980; Greaves et al., 2016; Guo et al., 2017); freshwater ecosystems (Iqbal et al., 2017); precipitation (Laniewski et al., 1998; Regnery and Püttmann, 2009; Regnery and Püttmann, 2010), indoor air and dust (Cequier et al., 2014; Hoffman et al., 2015; Tajima et al., 2014); remote arctic air (Salamova et al., 2014b; Sühring et al., 2016), food stuff (Poma et al., 2017) as well as human blood, breast milk and urine (Kim et al., 2014; Zhao et al., 2016; Carignan et al., 2013; Sundkvist et al., 2010; Van den Eede et al., 2015) reported the presence and occurrence of these chemicals, including their metabolites. Hoffman et al. (2017) also showed an increasing exposure trend to some OPEs based on urinary metabolite concentrations (Hoffman et al., 2017).

OPEs have been found in air in remote locations, indicating they are subject to long-range transport (Möller et al., 2011; Möller et al., 2012; Salamova et al., 2014b; Hallanger et al., 2015; Sühring et al., 2016). McPherson et al. (2004) point out that human and environmental impacts of the phosphate flame retardants (PFRs) cannot be ignored and Van der Veen and de Boer (2012) note there is evidence that some OPEs pose adverse biological effects, including in humans (e.g. hemolytic and reproductive effects of TCP and TCEP). There is now increased interest in understanding their environmental fate and transport (Greaves and Letcher, 2017).

It has been reported that flame retardants were not produced in Turkey (NIP, 2014; Yilmaz Civan, 2016). In Turkey, there are few studies on FRs in environmental compartments, and most focus on PBDEs. In homes and offices in the Istanbul area, levels of $\Sigma_{12}$ NBFRs (KurtKarakus et al., 2017) in indoor air ranged from $0.180-42.4 \mathrm{ng} / \mathrm{m}^{3}$, in indoor dust from $0.320-97.9 \mathrm{ng} / \mathrm{g}$ and in outdoor air from $0.720-2.80 \mathrm{ng} / \mathrm{m}^{3}$; and levels of $\Sigma_{13}$ OPEs in indoor dust ranged from 1.45-17.3 ng/g (Kurt-Karakus et al., 2014, 2015). To the best knowledge of the authors, there are no other studies on the organophosphate flame retardants in Turkish outdoor environmental compartments. This highlights the need to understand the levels, sources, and movement of flame retardants in the Turkish environment. As a developing and industrializing country, it is to be expected that there are significant levels of alternative flame retardants in the environment of Turkey. Therefore, the main aims of this work are a) to determine levels of OPEs in air and soil, b) to assess spatial/temporal differences in air concentrations, c) to assess potential source areas of OPEs in Bursa, an industrial city in Turkey.

\section{Materials and methods}

\subsection{Sampling locations}

Target OPEs were analyzed in air and soil samples from 8 sites in and near Bursa (Fig. 1). Bursa is the fourth biggest city of Turkey based on the 2015-2016 address-based population registration (2,901,396 people) of the Turkish Statistical Institute (TUIK, 2017) and the fifth biggest city of the country based on economic and social development index (Gul and Cevik, 2015). Detailed information on industrial zones and types of industries existing in the city is given elsewhere (Birgul et al. 2017) and in Fig. S4. Briefly, industrial production in Bursa has been focused on the textile, automotive, automotive spare parts, ready-to-wear garments, machinery and metal industries, dry-fresh and frozen foods, agriculture and service sectors. Besides the main automotive, textile/upholstery and furniture industry in Bursa, there are several sideindustries providing spare parts, interior design parts and fabrics as well as seats for automotive manufacturers. Air sampling sites were selected to be representative of the local/regional environment, but away from direct sources. The sampling sites were located in rural/background (Mount Uludag (MU)), urban (Bursa Technical University Osmangazi Campus (BTU) and Hamitler Area (HMT)), semiurban (Uludag University Campus (UUC) and Camlica Area (CAM)), industrial (Kestel Organised Industrial District (KOID) and Demirtas Organised Industrial District (DOID)) and agricultural (Ağaköy Village (AGK)) areas. Further details regarding the sampling sites are given in Supplemental Table S1. Soils were collected at each site on the day of first deployment of passive air samplers.

\subsection{Sampling methods}

\subsubsection{Passive air sampling}

Passive air samples were collected using a polyurethane foam disk (PUF-PAS) housed in the well characterize double sheltered assembly (Shoeib and Harner, 2002; Harner et al., 2004) which has been used in many field investigations for a variety of semivolatile organic pollutants (Wong et al., 2010, 2009; Jaward et al., 2004; Motelay-Massei et al., 2005; Gouin et al., 2005; Pozo et al., 2004) including OPEs (Abdollahi et al., 2017). These were PUF-PAS disks ( $51 \frac{1}{2}$ "Dia $\times 1 / 2$ " Thick Foam Pad (FR-Free), Tisch Environmental Inc., USA) suspended inside two stainless steel bowls, the upper inverted one being slightly larger to allow airflow between the two bowls (Harner et al., 2004. PUF-PAS were washed with water, Soxhlet extracted sequentially for 16-24 h with acetone, 1:1 acetone: hexane, and hexane, and dried in a vacuum desiccator. Cleaned PUF-PAS were stored in amber jars in a freezer. All glassware used was baked at $450{ }^{\circ} \mathrm{C}$ and solvent-washed immediately prior to use. Samplers were exposed at each of the eight sites for five sampling periods between February and December 2014, the samplers 


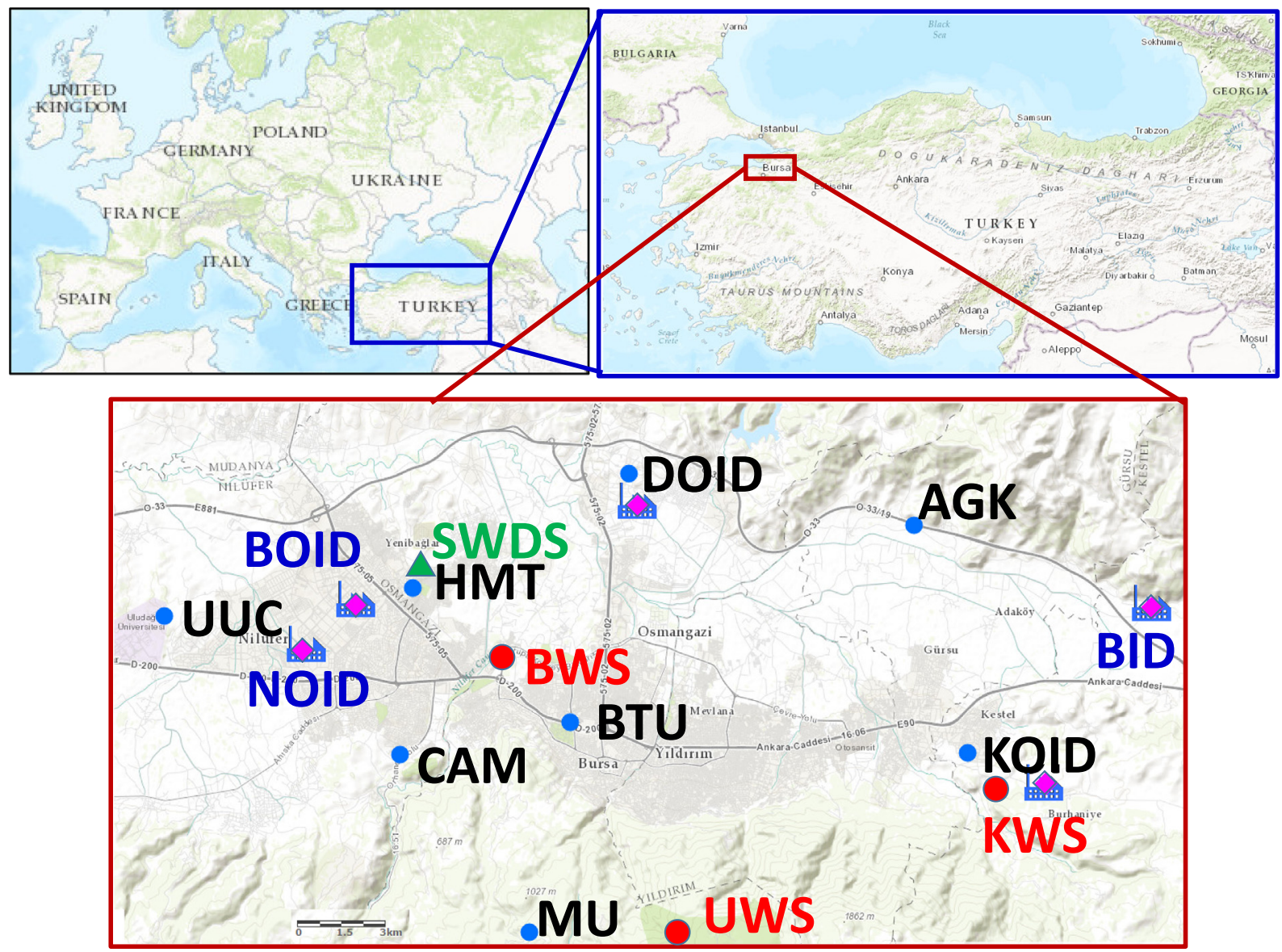

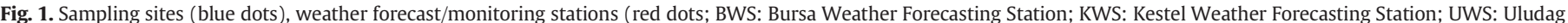

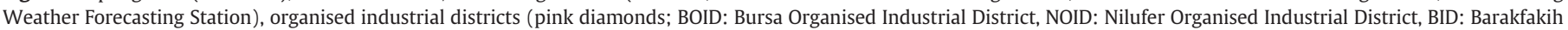
Organised Industrial District, KOID: Kestel Organised Industrial District, DOID: Demirtas Organised Industrial District) and Bursa city solid waste disposal site (SWDS; green triangle).

were exposed for about the same amount of days at each site per period and ranged from 43 to 75 days per sampling period, for a total of 40 samples (see Table 1 ).

PUF-PAS were spiked with a depuration chemicals mixture consisting of three PCB congeners not found in technical mixtures (PCB-34, 62 and 204) at least 3 days prior to deployment. Air volumes for passive sampling were estimated using the depuration rates of these performance reference compounds according to published protocols (Gouin et al., 2005; Pozo et al., 2004; Harner et al., 2004; Shoeib and Harner, 2002) and using the template provided by GAPS Network (Harner, 2016; Parnis et al., 2016) for calculations. A recent PUF-PAS calibration study for OPEs (Abdollahi et al., 2017) showed that these compounds did not reach equilibrium over the first 90 days which is much longer than our deployment period. Sampling rates for individual events were used to derive total air volumes; these rates ranged from 3.33 to $11.15 \mathrm{~m}^{3} \mathrm{~d}^{-1}$ with a mean of $6.21 \pm 1.69 \mathrm{~m}^{3} \mathrm{~d}^{-1}$. Abdollahi et al. (2017) reported PUF-PAS sampling rate $\left(\mathrm{m}^{3} /\right.$ day) for selected OPEs to be between 2.2 and $6.1 \mathrm{~m}^{3} /$ day. Final concentrations were calculated by dividing total amounts of chemicals accumulated in the sampler by the air volumes during the sampling period.

\subsubsection{Soil sampling}

Surface soil was collected at each of the air sampling sites on the day of first deployment of PUF-PAS. For this purpose, the closest feasible site for soil collection was identified and 3-5 samples of bare soil (plant material discarded) were collected with a metal trowel from the surface to $5-10 \mathrm{~cm}$. These were pooled and sieved through a 2-mm stainless steel mesh to provide one homogeneous composite sample for that site. This resulted in a total of 8 pooled soil samples representing each of the sampling sites. For each pooled sample, several subsamples were dried at $105^{\circ} \mathrm{C}$ for moisture (ASTM, 2000a) content determination and the percent organic carbon was determined by ignition loss on combustion at $440{ }^{\circ} \mathrm{C}$ (ASTM, 2000b).

\subsection{Chemical analysis}

\subsubsection{Sources of chemicals}

Solvents and reagents used were chromatographic or analytical quality and purchased from Merck (Merck EMD Millipore, USA). Previously used abbreviations (PUAB) and practical abbreviations (PRAB) (Bergman et al., 2012) of chemicals of interest are shown in SI Table 2. PRABs of labeled or deuterated chemicals are given in bolded in parenthesis and only PRABs have been used in the main text of the current study. Tricresyl phosphate (TMPP), triphenyl phosphate (TPHP), tris(1chloro-2-propyl) phosphate (TCPP $=$ tris(1-chloro-2-propyl) phosphate (TCIPP) + Bis(2-chloro-1-methylethyl) (2-chloropropyl) phosphate), Tris(1,3-dichloro-2-propyl) phosphate (TDCPP), tris(2-butoxyethyl) phosphate (TBOEP), tris(2-chloroethyl) phosphate (TCEP), Tris(2ethylhexyl) phosphate (TEHP) and tris(2-isopropylphenyl) phosphate (T2IPPP) were purchased from Wellington Laboratories Guelph, Ontario, Canada). Labeled recovery surrogate chemicals $\left(d_{27}\right.$ - tris butyl phosphate (TBP or TNBP,), $\mathrm{d}_{21^{-}}$tris propyl phosphate (TPrP or TPP,), $\mathrm{d}_{12^{-}}$tris chloroethyl phosphate (TCEP), $\left[{ }^{13} \mathrm{C}_{18}\right]$ - tris phenyl phosphate (TPhP or TPHP;), [ $\left.{ }^{13} \mathrm{C}_{2}\right]$ - tris(2-butoxyethyl) phosphate (TBEP or TBOEP) and $\left[{ }^{13} \mathrm{C}_{12}\right]$-PCB105 (internal standard)) were obtained from Cambridge Isotope Laboratories (Andover, MA, U.S.A.). Supelclean ${ }^{\mathrm{TM}}$ ENVI $^{\mathrm{TM}}$-Florisil ${ }^{\circledR}$ 
Table 1

Concentrations of OPEs in air $\left(\mathrm{pg} / \mathrm{m}^{3}\right)$ : background site: MU; rural/agricultural: AGK; suburban: UUC, CAM; urban: BTU, HMT; industrial: KOID, DOID.

\begin{tabular}{|c|c|c|c|c|c|c|c|c|c|c|c|c|c|}
\hline & Sampling & Deployment & & & & & & & & Total & alkylated & halogenated & aryl \\
\hline Site & Phase & time (days) & TCEP & ТСРP & ТPHP & ТВОЕР & TEHP & T2іPPP & TDCPP & ¿OPEs & ¿OPEs & ¿OPEs & ¿OPES \\
\hline MU & Phase $1^{\mathrm{a}}$ & 66 & 45 & 114 & 77 & 3601 & 62 & 74 & $\mathrm{BD}$ & 3973 & 3663 & 159 & 152 \\
\hline AGK & Phase 1 & 65 & 125 & 1213 & 173 & $\mathrm{BD}$ & 340 & 113 & $\mathrm{BD}$ & 1963 & 340 & 1338 & 285 \\
\hline UUC & Phase 1 & 65 & 102 & 452 & 173 & 7726 & 273 & $\mathrm{BD}$ & $\mathrm{BD}$ & 8726 & 7999 & 554 & 173 \\
\hline CAM & Phase 1 & 66 & 79 & 530 & 142 & 3674 & 26 & $\mathrm{BD}$ & $\mathrm{BD}$ & 4451 & 3700 & 609 & 142 \\
\hline BTU & Phase 1 & 66 & 109 & 770 & 155 & $\mathrm{BD}$ & 41 & BD & $\mathrm{BD}$ & 1075 & 41 & 879 & 155 \\
\hline HMT & Phase 1 & 66 & 143 & 503 & 320 & 4270 & 101 & $\mathrm{BD}$ & $\mathrm{BD}$ & 5336 & 4371 & 646 & 320 \\
\hline KOID & Phase 1 & 62 & 37 & 794 & 130 & 1671 & 63 & 80 & $\mathrm{BD}$ & 2775 & 1734 & 831 & 211 \\
\hline DOID & Phase 1 & 65 & $\mathrm{BD}$ & 853 & 263 & 5868 & 222 & 122 & $\mathrm{BD}$ & 7327 & 6090 & 853 & 384 \\
\hline MU & Phase $2^{\mathrm{b}}$ & 58 & 53 & 100 & 66 & 2781 & 37 & $\mathrm{BD}$ & $\mathrm{BD}$ & 3035 & 2817 & 152 & 66 \\
\hline AGK & Phase 2 & 61 & 115 & 180 & 136 & 6033 & $\mathrm{BD}$ & BD & $\mathrm{BD}$ & 6464 & 6033 & 295 & 136 \\
\hline UUC & Phase 2 & 60 & 61 & 249 & 113 & $\mathrm{BD}$ & 51 & $\mathrm{BD}$ & $\mathrm{BD}$ & 474 & 51 & 310 & 113 \\
\hline CAM & Phase 2 & 61 & $\mathrm{BD}$ & 292 & 98 & 4659 & $\mathrm{BD}$ & $\mathrm{BD}$ & $\mathrm{BD}$ & 5049 & 4659 & 292 & 98 \\
\hline BTU & Phase 2 & 62 & 71 & 4097 & 206 & 9690 & 86 & $\mathrm{BD}$ & $\mathrm{BD}$ & 14,151 & 9776 & 4168 & 206 \\
\hline HMT & Phase 2 & 61 & $\mathrm{BD}$ & 195 & 183 & 4818 & $\mathrm{BD}$ & 192 & $\mathrm{BD}$ & 5387 & 4818 & 195 & 374 \\
\hline KOID & Phase 2 & 68 & $\mathrm{BD}$ & 730 & 287 & 8808 & 69 & $\mathrm{BD}$ & $\mathrm{BD}$ & 9895 & 8878 & 730 & 287 \\
\hline DOID & Phase 2 & 61 & 136 & 851 & 148 & 6790 & 9 & $\mathrm{BD}$ & $\mathrm{BD}$ & 7934 & 6798 & 987 & 148 \\
\hline MU & Phase $3^{c}$ & 66 & 73 & 144 & 99 & 9696 & $\mathrm{BD}$ & $\mathrm{BD}$ & $\mathrm{BD}$ & 10,013 & 9696 & 218 & 99 \\
\hline AGK & Phase 3 & 65 & 102 & 2647 & 93 & 5958 & 11 & $\mathrm{BD}$ & $\mathrm{BD}$ & 8810 & 5969 & 2749 & 93 \\
\hline UUC & Phase 3 & 76 & 58 & 196 & 96 & 9231 & 155 & BD & $\mathrm{BD}$ & 9736 & 9386 & 254 & 96 \\
\hline CAM & Phase 3 & 68 & 110 & 810 & 209 & 17,820 & 189 & $\mathrm{BD}$ & $\mathrm{BD}$ & 19,139 & 18,009 & 921 & 209 \\
\hline BTU & Phase 3 & 67 & 39 & 220 & 54 & 802 & $\mathrm{BD}$ & $\mathrm{BD}$ & $\mathrm{BD}$ & 1115 & 802 & 259 & 54 \\
\hline HMT & Phase 3 & 67 & 68 & 855 & 227 & 17,921 & 34 & BD & $\mathrm{BD}$ & 19,104 & 17,955 & 923 & 227 \\
\hline KOID & Phase 3 & 66 & 78 & 214 & 302 & 13,432 & $\mathrm{BD}$ & $\mathrm{BD}$ & $\mathrm{BD}$ & 14,026 & 13,432 & 293 & 302 \\
\hline DOID & Phase 3 & 65 & $\mathrm{BD}$ & 256 & 237 & 3413 & 112 & $\mathrm{BD}$ & $\mathrm{BD}$ & 4019 & 3525 & 256 & 237 \\
\hline MU & Phase $4^{\mathrm{d}}$ & 64 & 112 & 385 & 147 & 15,391 & 23 & $\mathrm{BD}$ & $\mathrm{BD}$ & 16,057 & 15,413 & 497 & 147 \\
\hline AGK & Phase 4 & 64 & 76 & 1142 & 111 & $\mathrm{BD}$ & 9 & $\mathrm{BD}$ & $\mathrm{BD}$ & 1339 & 9 & 1218 & 111 \\
\hline UUC & Phase 4 & 64 & $\mathrm{BD}$ & 528 & 127 & 11,553 & 87 & $\mathrm{BD}$ & $\mathrm{BD}$ & 12,294 & 11,639 & 528 & 127 \\
\hline CAM & Phase 4 & 64 & 55 & 169 & 81 & 3032 & $\mathrm{BD}$ & $\mathrm{BD}$ & $\mathrm{BD}$ & 3336 & 3032 & 223 & 81 \\
\hline BTU & Phase 4 & 64 & 140 & 1203 & 208 & 16,533 & 138 & $\mathrm{BD}$ & $\mathrm{BD}$ & 18,222 & 16,671 & 1343 & 208 \\
\hline HMT & Phase 4 & 65 & 69 & 1021 & 168 & $\mathrm{BD}$ & 12 & $\mathrm{BD}$ & $\mathrm{BD}$ & 1270 & 12 & 1090 & 168 \\
\hline KOID & Phase 4 & 64 & 89 & 1103 & 263 & 9773 & 55 & $\mathrm{BD}$ & $\mathrm{BD}$ & 11,283 & 9828 & 1192 & 263 \\
\hline DOID & Phase 4 & 64 & 69 & 2737 & 171 & 3416 & 53 & $\mathrm{BD}$ & $\mathrm{BD}$ & 6446 & 3468 & 2806 & 171 \\
\hline MU & Phase $5^{e}$ & 49 & 78 & 123 & 104 & 5742 & 8 & $\mathrm{BD}$ & $\mathrm{BD}$ & 6054 & 5749 & 201 & 104 \\
\hline AGK & Phase 5 & 49 & 84 & 407 & 114 & 7761 & $\mathrm{BD}$ & $\mathrm{BD}$ & $\mathrm{BD}$ & 8365 & 7761 & 490 & 114 \\
\hline UUC & Phase 5 & 43 & 110 & 808 & 175 & 3901 & 65 & 88 & $\mathrm{BD}$ & 5146 & 3966 & 918 & 263 \\
\hline CAM & Phase 5 & 49 & 61 & 793 & 123 & 6225 & $\mathrm{BD}$ & 64 & $\mathrm{BD}$ & 7266 & 6225 & 854 & 187 \\
\hline BTU & Phase 5 & 49 & 124 & 1332 & 162 & 2288 & 493 & 85 & $\mathrm{BD}$ & 4484 & 2781 & 1456 & 247 \\
\hline HMT & Phase 5 & 49 & 141 & 1354 & 202 & 1674 & 46 & $\mathrm{BD}$ & $\mathrm{BD}$ & 3416 & 1720 & 1495 & 202 \\
\hline KOID & Phase 5 & 60 & 107 & 335 & 146 & 8593 & 77 & $\mathrm{BD}$ & $\mathrm{BD}$ & 9258 & 8671 & 442 & 146 \\
\hline DOID & Phase 5 & 49 & 128 & 4918 & 246 & 3823 & 75 & $\mathrm{BD}$ & $\mathrm{BD}$ & 9189 & 3897 & 5046 & 245 \\
\hline \multirow[t]{5}{*}{ Annual } & Average & & 90 & 891 & 163 & 7096 & 97 & 102 & & 7435 & 6285 & 967 & 184 \\
\hline & Std Dev & & 31 & 1034 & 67 & 4652 & 108 & 41 & & 50,445 & 4951 & 1047 & 82 \\
\hline & Geomean & & 84 & 552 & 150 & 5670 & 58 & 97 & & 5577 & 3071 & 644 & 166 \\
\hline & Median & & 81 & 630 & 152 & 5958 & 63 & 86 & & 6455 & 5284 & 688 & 170 \\
\hline & Range & & BD-143 & $100-4918$ & $54-320$ & BD-17,921 & BD-493 & BD-192 & & $474-19,139$ & $9.2-18,009$ & $159-4168$ & $54-303$ \\
\hline
\end{tabular}

\footnotetext{
a Feb-Apr.

b Apr-Jun.

c Jun-Aug.

d Aug-Oct.

e Oct-Dec.
}

SPE cartridges with Teflon frits $(500 \mathrm{mg} / 3 \mathrm{~mL})$ were purchased from Sigma Aldrich (St Louis, MO, USA).

\subsubsection{Extraction and cleanup of air and soil samples}

The PUF-PAS were spiked with surrogate compounds (50 ng each) to monitor recoveries, then Soxhlet extracted for $16 \mathrm{~h}$ with $200 \mathrm{~mL}$ of 1:1 dichloromethane:hexane. Extracts were concentrated by rotary evaporation and nitrogen blow-down to $1 \mathrm{~mL}$ and solvent-exchanged into isooctane.

Table 2

Pearson correlation coefficients for measured OPEs in air.

\begin{tabular}{llllll}
\hline & TCEP & TCPP & TPHP & TBOEP & TEHP \\
\hline TCEP & - & 0.29 & 0.27 & 0.11 & 0.23 \\
TCPP & 0.29 & - & 0.27 & 0.04 & 0.05 \\
TPHP & 0.27 & 0.27 & - & $\mathbf{0 . 3 2}$ & 0.19 \\
TBOEP & 0.11 & 0.04 & $\mathbf{0 . 3 2}$ & - & 0.01 \\
TEHP & 0.23 & 0.05 & - & 0.01 & - \\
\hline
\end{tabular}

Bold, italicized values indicate that the correlation was statistically significant $(\mathrm{p}<0.05)$.
Soil samples ( $30 \mathrm{~g}$ wet weight) were mixed with sodium sulfate, spiked with the surrogate mixture and homogenized with a mortar and pestle. The mixture was Soxhlet extracted for $16 \mathrm{~h}$ with 1:1 dichloromethane: hexane mixture. Extracts were concentrated and transferred to isooctane by rotary evaporation and nitrogen blow-down to $1 \mathrm{~mL}$.

Cleanup of extracts was done by solid phase extraction (SPE) using Florisil SPE cartridges by a modification of method reported by Van den Eede et al. (2012) and Hoffman et al. (2015). The cartridge was cleaned with $8 \mathrm{~mL}$ methanol followed by $4 \mathrm{~mL}$ hexane, the sample was added in a 1-mL volume and the cartridge was eluted with $8 \mathrm{~mL}$ hexane followed by $10 \mathrm{~mL}$ ethyl acetate. Both eluates were combined, volume was reduced to $1 \mathrm{~mL}$ on a rotary evaporator and transferred to isooctane by nitrogen blow-down. $50 \mathrm{ng}$ of $\left[{ }^{13} \mathrm{C}_{12}\right]-\mathrm{PCB} 105$ was added as the internal standard.

\subsubsection{Quantitative analysis}

All analyses were done by gas chromatography-mass selective detector operating in electron impact (GC-EI-MS) using an Agilent 6890 
GC-5973 and 5975 Mass Selective Detector (MSD). Quantitative analysis was done on a DB-5 column (J\&W, Agilent Technologies, $30 \mathrm{~m}, 0.25 \mathrm{~mm}$ i.d., $0.25 \mu \mathrm{m}$ film thickness) with an injector temperature of $200{ }^{\circ} \mathrm{C}$. The temperature program was: initial temperature $70{ }^{\circ} \mathrm{C}$ ( $1.0 \mathrm{~min}$ hold $) ; 10$ ${ }^{\circ} \mathrm{C} \mathrm{min}-1$ to $170{ }^{\circ} \mathrm{C}$, hold for $3 \mathrm{~min}$; then $10^{\circ} \mathrm{C} \mathrm{min}^{-1}$ to $230{ }^{\circ} \mathrm{C}$, hold for $5.0 \mathrm{~min} ; 5^{\circ} \mathrm{C} \mathrm{min}^{-1}$ to $250^{\circ} \mathrm{C}$, no hold; and $10^{\circ} \mathrm{C} \mathrm{min}{ }^{-1}$ to $310^{\circ} \mathrm{C}$, hold for $3 \mathrm{~min}$. Samples were injected splitless ( $2 \mu \mathrm{L}$, split opened after $2.0 \mathrm{~min})$. Other instrument conditions were: the helium carrier gas at $1.0 \mathrm{~mL} \mathrm{~min}^{-1}$ transfer line temperature $280^{\circ} \mathrm{C}$, ion source $230^{\circ} \mathrm{C}$ and quadrupole $150{ }^{\circ} \mathrm{C}$. Target peaks were accepted if the target/qualifying ion ratio was within $20 \%$ of standards.

\subsection{Quality assurance/quality control}

Instrumental detection limits (IDLs) were estimated by injecting low concentrations of target analytes until a small peak at 3:1 signal: noise ratio was obtained. These IDLs are expressed in $\mathrm{pg} \mathrm{g}^{-1}(\mathrm{dw})$ soil and $\mathrm{pg}$ $\mathrm{m}^{-3}$ air. The latter calculation was done assuming extract volumes of $1.0 \mathrm{~mL}$, air volume of $500 \mathrm{~m}^{3}$ and $20 \mathrm{~g}$ (dw) of soil.

Laboratory blank samples were run every 10 samples for PUF-PAS ( $n$ $=5$ ) whereas a total of 3 field blank samples were prepared by taking a clean PUF-PAS sample to the field, exposing to the air for approx. $1 \mathrm{~min}$ and taking back to the laboratory in a sealed jar. A total of 5 laboratory blank samples were prepared for soils, consisting of pre-cleaned anhydrous sodium sulfate. All blank samples were treated in the same manner as PUF-PAS and soil samples. The limits of detection (LOD) for $500 \mathrm{~m}^{3}$ of air and $20 \mathrm{~g}(\mathrm{dw})$ soil for the target OPEs were calculated as the mean blank $+3 \times$ S.D. LODs in air and soil for target compounds are shown in Table S1. Sample amounts were compared to LODs and IDLs and if a peak was observed for a sample constituent but the quantity was $<$ LOD, one half of the LOD was used for statistical purposes. If no peak was observed for a sample constituent ( $<$ IDL), the air or soil concentration was considered zero ( $\mathrm{nd}=$ not detected).

To check the performance of the entire method and to control recovery rates, passive air samples, blank PUF-PAS and soils were spiked before extraction with the recovery solution described above. Mean recoveries were: $d_{27}$-TNBP (80-103\%), $d_{21}$-TPP (81-101\%), $d_{12}$-TCEP (85-108\%), $\left[{ }^{13} \mathrm{C}_{18}\right]$-TPHP (84-106\%), and $\left[{ }^{13} \mathrm{C}_{2}\right]$-TBOEP (65-89\%), with RSD all below $10 \%$. Target chemical recovery test was conducted by spiking known amount of target chemicals on a PUF-PAS disk $(n=3)$ and processing for the entire method. Recovery of all target chemicals was $>80 \%$.

\subsection{Meteorological data}

Daily wind direction data for the period between February and November 2014 was obtained from General Directorate of Bursa District Weather Forecast and Monitoring. There were only 3 weather forecast stations, namely Kestel Weather Station (KWS), Bursa Weather Station (BWS) and Uludag Weather Station (UWS) with available data on wind direction. The sampling stations are grouped based on the distances of sampling sites to these weather forecast stations (Fig. S1). We have calculated dominant wind direction for each month of the periods (Fig. S2a, b and c) and for the period of February-November (overall course of the study). Based on overall course of the study dominant wind directions, we prepared Fig. S3 which shows dominant wind direction of the air masses that each sampling station received.

\section{Results and discussion}

\subsection{OPEs in air}

Concentrations of OPEs in ambient air at the eight sampling locations for each sampling phase are shown in Table 1. TCEP, TCPP, TPHP, TBOEP, TEHP, and T2iPPP were detected while TDCPP was below detection limit. Frequency of detection was TCPP and TPHP (100\%) > TBOEP
(88\%) > TCEP (85\%) > TEHP (78\%) > T2iPPP (20\%), and concentrations were in the order TBOEP $\gg$ TCPP $>$ TPHP $>$ TEHP $>$ TCEP. Annual geometric means of concentrations at all sites over all five sampling periods and ranges (excluding non-detects) were $\left(\mathrm{pg} / \mathrm{m}^{3}\right)$ : TBOEP 5670 $(802-17,900)>$ TCPP $552(100-4900)>$ TPHP $150(54-320)>$ TEHP 58 (9-493) > TCEP 84 (37-143). T2IPPP was detected at the lowest frequency (20\%) so the same statistical treatment was not applied to it to calculate an annual average. For the $20 \%$ of cases where it was detected, its mean concentration was $102 \mathrm{pg} / \mathrm{m}^{3}$ and the range for those $8 \mathrm{sam}-$ ples was $64-192 \mathrm{pg} / \mathrm{m}^{3}$. In terms of percentage of total OPEs, TBOEP was the dominant flame retardant in 34 of 40 individual samples, ranging in those cases from $40 \%$ to $96 \%$ of the total. When averaged annually per site, the percent of TBOEP relative to total OPEs ranged from $67 \%$ (DOID) to $95 \%$ (MU) while for TCPP the range was 2.2\% (MU) to $28 \%$ (DOID). Fig. 2, which shows the annual mean of each OPE per site (based on the concentrations of each of the five sampling phases), illustrates the predominance of TBOEP in the air in the study region.

OPEs can be categorized by whether they are halogenated, alkylated or aryl OPEs. Of the OPEs measured in this study, TCEP and TCPP are halogenated, TBOEP and TEHP are alkylated, and TPHP and T2iPPP are aryl OPEs. OPEs in air at all sites are dominated by the alkylated compounds, with much lower quantities of halogenated and aryl OPEs. Annual average concentrations of alkylated OPEs as a percentage of total OPEs ranged from 68\% (DOID) to 95\% (MU), for halogenated OPEs the percentage ranged from 3.1\% (MU) to 29\% (DOID), while for aryl OPEs the range was $1.4 \%(\mathrm{MU})$ to $3.7 \%$ (HMT). Interestingly, the rural/agricultural site (AGK) which was expected to be similar to the background site had relative contributions more similar to the industrial and urban sites. Our results are different from those of Salamova et al. (2014a) who reported that air concentrations of OPEs were dominated in urban sites by chlorinated OPEs while in rural sites the predominant OPEs were the nonchlorinated ones. In our study, non-chlorinated OPEs were dominant in every type of environment.

Fig. 3 compares the annual median concentrations of OPEs (total and by type) measured in air in this study. Annual median concentrations of total OPEs were fairly uniform and influenced mainly by the alkylated OPEs, namely TBEOP. Interestingly, the annual median of total OPEs at the background site was not the lowest as might be expected and is instead similar to most other sites. The background site, while removed from the city, was at a high elevation. The atmospheric transport of organic pollutants to and deposition in higher elevations has been shown in other locations (Shunthirasingham et al., 2011; LeNoir et al., 1999). Thus, OPEs from the urban and industrial areas of Bursa may be undergoing transport to higher elevations (see discussion below on wind direction). Also, although this site was located away from the city, there is considerable vehicular traffic in the vicinity from people traveling to Mount Uludag skiing area located farther up the mountain. This may also partly account for the high levels at this site. Higher concentrations of OPEs have also been observed in samples from higher elevations, and these have been attributed to higher sampling rates due to higher wind speeds. Wind speeds were not available in this study but the higher concentrations at the background site may be partly due to this. The annual median of total OPEs at the rural/agricultural site (AGK) was likewise similar to, or even higher than, some urban and suburban sites, again indicating the likelihood of input via atmospheric transport from urban and suburban areas.

Concentrations of halogenated and aryl OPEs are not as uniform as the alkylated OPEs. For halogenated OPEs, concentrations were higher at DOID, BTU and AGK compared to the other sites while for aryl OPEs there seems to be a general trend of increasing median concentrations from the background to the industrial sites. $t$-test calculations were carried out to determine if there were statistically significant differences between sites. There were no statistically significant differences $(p>$ 0.05 ) between sites when comparing total OPEs and alkylated OPEs. There were statistically significant differences $(p<0.05)$ for aryl-OPEs only between MU (background site) and HMT (urban), KOID 
MU

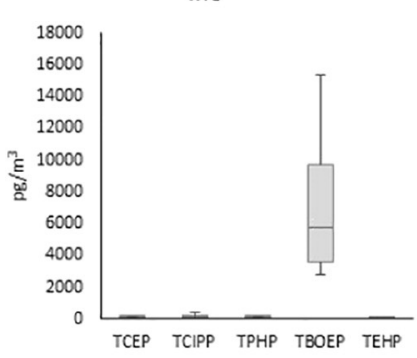

BTU

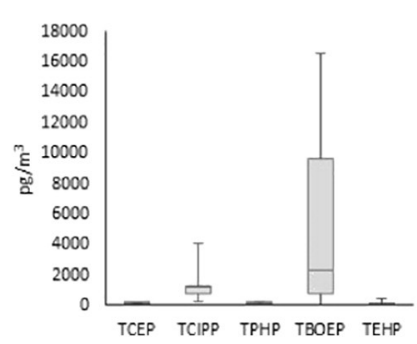

AGK

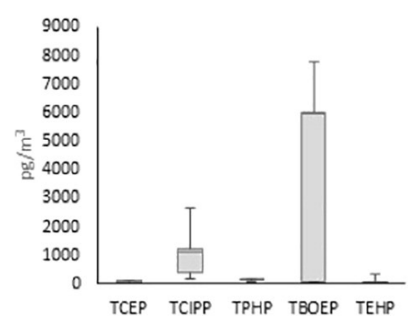

HMT

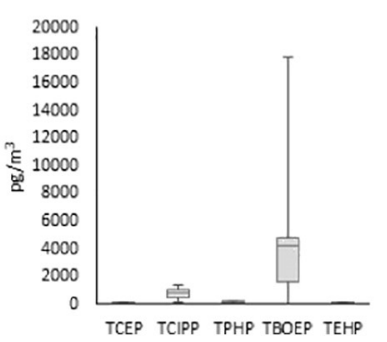

UUC

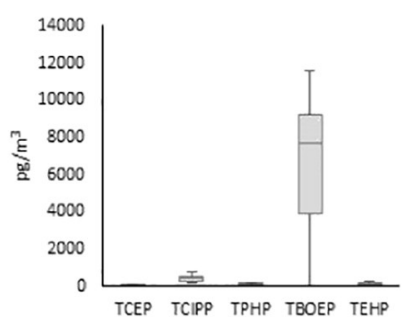

KOID

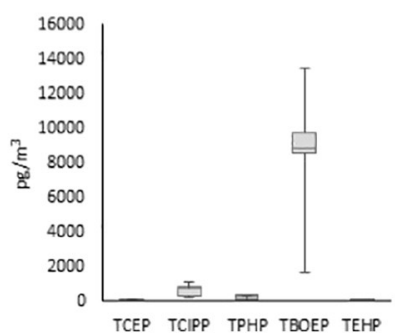

CAM

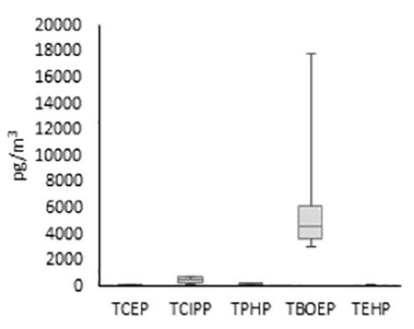

DOID

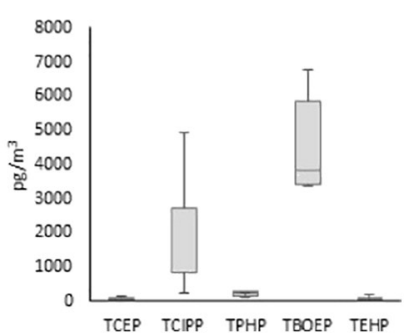

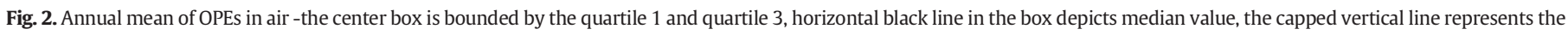
range of the data (background site: MU; rural/agricultural: AGK; suburban: UUC, CAM; urban: BTU, HMT; industrial: KOID, DOID).

(industrial) and DOID (industrial) and between CAM (suburban) and the same three sites; and for halogenated OPEs between MU and HMT and KOID. This is in agreement with $t$-test calculations carried out to determine if there were any statistically significant differences $(p<0.05)$ in annual concentrations of each individual OPE between sites. This was the case only for TPHP (the dominant aryl-OPE) between the same sites (MU and HMT/KOID/DOID and CAM and HMT/KOID/DOID) and as well as AGK (rural/agricultural) and HMT/KOID/DOID and UUC (suburban) and two of those sites (HMT/DOID); and for TCPP between MU and HMT/KOID.
As noted previously, Bursa is an important industrial centre in Turkey. It has also experienced a major construction boom for many years. Therefore, the OPEs measured in this study are likely due to their use in these activities (construction, automobile and associated industries, textile industry, metallurgy, etc.), some of which are widespread in the Bursa metropolitan area. The similarity in OPE profiles (as indicated by the lack of statistically significant differences between most two-site comparisons) suggests similar sources of these chemicals at all sites. It also suggests the possibility that air circulation patterns in the Bursa region may mix OPEs released by all the sources and make the

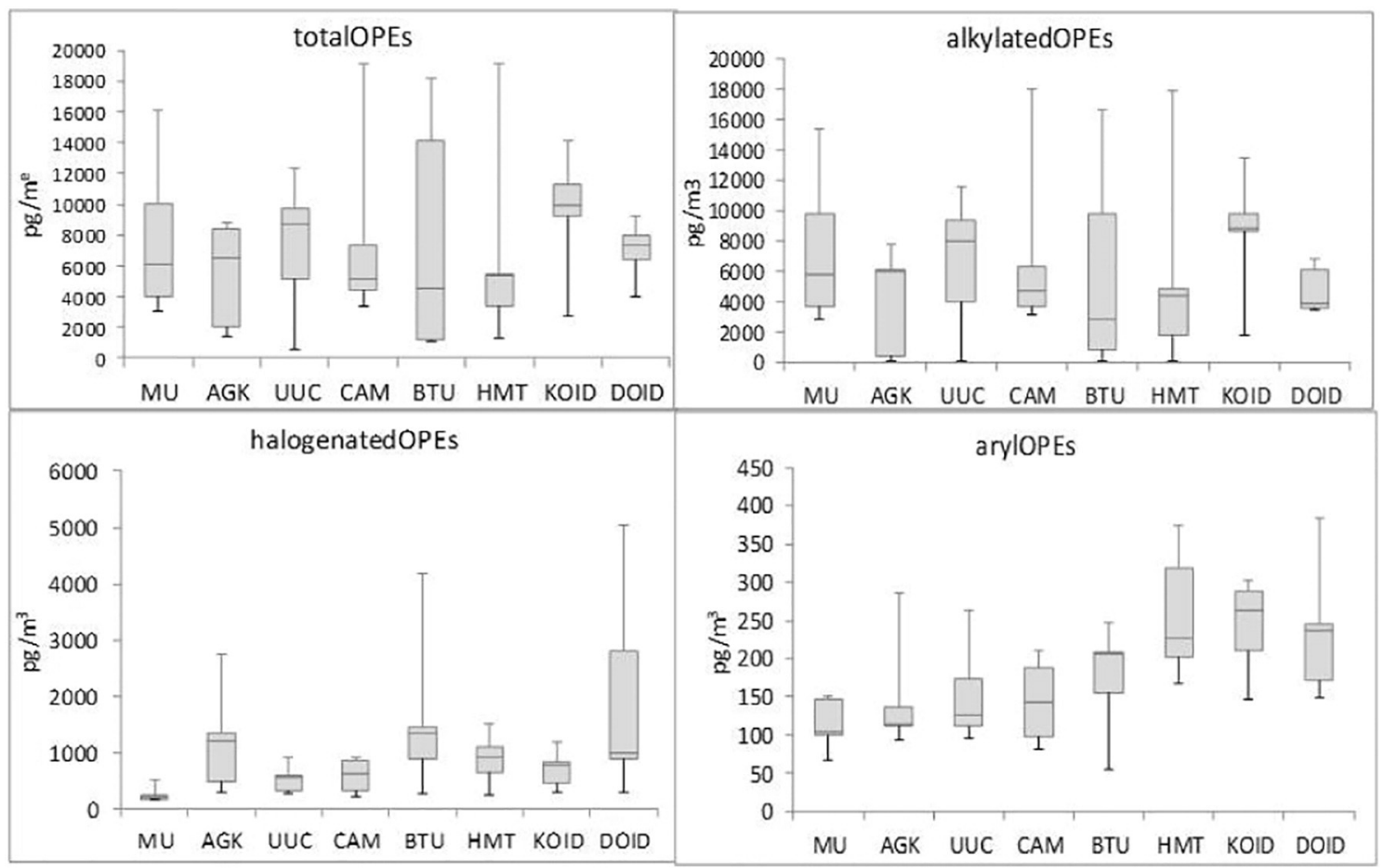

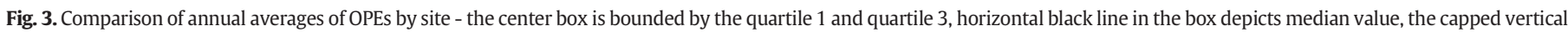
line represents the range of the data (background: MU; rural/agricultural: AGK;suburban: UUC, CAM; urban: BTU, HMT; industrial: KOID,DOID). 
concentrations more homogeneous. The statistically significant difference in levels of TPHP between the industrial sites (KOID and DOID) and one urban site (HMT) and 4 of the other 5 sites (background, agricultural, and suburban) may be due to higher quantities of this OPE being used at industrial and urban areas near to the sampling sites. In general, there is a trend of decreasing levels of TPHP from the industrial sites through the background site, supporting the hypothesis that the industrial and urban sites were close to point sources of aryl OFRs. The statistically significant differences in levels of the chlorinated TCPP between the background site (MU) and the urban HMT and industrial (KOID) may be due to the same factor. The levels of OPEs at the background and rural sites suggest atmospheric transport of these chemicals from sources to the surrounding areas.

As noted above, the high levels of OPEs at the background site may be explained by atmospheric transport from urban and industrial sites. To determine this, wind direction data was obtained from the Bursa District Weather Forecast and Monitoring Office. Only three weather forecast stations had available wind direction data - Kestel Weather Station (KWS), Bursa Weather Station (BWS) and Uludag Weather Station (UWS). Therefore, we grouped the sampling stations based on the distances of sampling sites to these weather forecast stations (Fig. S1). We calculated dominant wind direction for each month of the sampling phases and for the overall February - November period at each of the weather forecast stations (Fig. S2a-c). As seen in Figs. S2a-c and S3, wind direction supports the hypothesis that OPEs undergo atmospheric transport from urban to rural sites (assuming that predominant wind direction at each sampling site is reflected by the predominant wind direction of the nearest weather forecast station). MU, the background sampling site, was affected by winds predominantly from north and north-west. Bursa City and its districts are located north and northwest of MU and could be the source of the elevated levels of OPEs measured at this site. As noted previously, median levels of total OPEs and relative contributions of each type of OPEs at AGK (the rural/agricultural site) were similar to levels at urban and suburban sites. Figs. S2a-c and S3 show that the predominant wind direction at AGK and KOID was from the south-east. KOID is south-east of AGK, indicating that OPEs are likely undergoing atmospheric transport from the former to the latter.

There are relatively few measurements of OPEs in the environment. Salamova et al. (2014a) recently reported values for these compounds in air on the U.S. side of the Great Lakes. Concentrations of LOPEs (12 compounds) ranged from $120 \pm 18 \mathrm{pg} / \mathrm{m}^{3}$ to $2100 \pm 400 \mathrm{pg} / \mathrm{m}^{3}$ in airborne particulates collected with high-volume air samplers. These values are lower than the values in Bursa air, which ranged from 451 to $19,139 \mathrm{pg} / \mathrm{m}^{3}$. Concentrations in Bursa are also higher than those reported by Möller et al. (2012) for airborne particulates over the polar regions (with particulate air concentrations of individual OPEs ranging from $10 \mathrm{pg} / \mathrm{m}^{3}-2900 \mathrm{pg} / \mathrm{m}^{3}$ ). Ohura et al. (2006) reported a median concentration of TCEP of $9.39 \mathrm{ng} / \mathrm{m}^{3}$, higher than the values for this compound in Bursa. Mihajlovic and Fries (2012) reported calculated average air levels of TCEP of $5.4 \mathrm{pg} / \mathrm{m}^{3}$ and TCPP of $990 \mathrm{pg} / \mathrm{m}^{3}$ in the city centre of Osnabrueck, Germany. In Bursa, the annual average of TCEP was higher at $84 \mathrm{pg} / \mathrm{m}^{3}$ and the TCPP levels were similar at $888 \mathrm{pg} / \mathrm{m}^{3}$. Total OPEs measured in air in Bursa are similar to a recent report of OPEs in air measured in ship- and land-based samples from the Canadian Arctic (Sühring et al., 2016).

Salamova et al. (2014a) reported air concentrations of OPEs were dominated in urban sites by chlorinated OPEs while in rural sites the predominant OPEs were the non-chlorinated ones, contrary to our results in which air concentrations are dominated by non-chlorinated OPEs at all sites. Sühring et al. (2016) reported that in both ship- and land-based samples from the Canadian Arctic chlorinated OPEs were dominant in almost all samples and Möller et al. (2012) also reported the predominance of chlorinated OPEs over polar regions, contrary to the results in this study. These differences may be due to differences in usage patterns in Turkey compared to other locations.

\subsection{Seasonal variations of OPEs in air}

Since there are not large spatial differences, the seasonal patterns were determined using the geometric means (combining all 8 sites) of total, alkylated, halogenated and aryl OPEs concentrations plotted against average temperature of that sampling period. Fig. 4 shows the results. The relationship between concentrations and temperature is not directly proportional. For total OPEs the mean concentrations during the warmer months (April through October) were higher than the colder February-April period, but mean concentration was higher in October-December (average temperature $11.8^{\circ} \mathrm{C}$ ) than in April-June (average temperature $18.7^{\circ} \mathrm{C}$ ) and August-October (average temperature $19.5^{\circ} \mathrm{C}$ ). The pattern for alkylated OPEs was most similar to total OPEs, except for much lower mean concentration of the former in August-October. In the case of halogenated OPEs, mean concentrations were higher during the colder October-December and February-April periods than the warmer April-June and June-August periods; mean concentration during the warmest August-October period was similar to the October-December value. For aryl OPEs the mean concentrations were higher during the colder sampling periods than the warmer periods. Mean concentrations were only significantly different $(p<0.05)$ only between February-April and June-August for total OPEs and alkylated OPEs. Halogenated and aryl OPEs concentrations are not significantly proportional to temperature $(p>0.05)$. These results suggest that emission from sources may not be driven by the vapour pressures of these chemicals. The levels in air may be a factor of quantities of each type used near the sampling sites.

Fig. 5a and b show the seasonal levels of total, alkylated, halogenated, and aryl OPEs at each sampling site. There are clear differences between the sites for all cases. In general, there is more uniformity between the sites for aryl OPEs than for alkylated or halogenated OPEs. For alkylated OPEs, while in general (with the exception of AGK) higher levels were measured in the warmer months, the patterns were markedly different for different sites. Levels of alkylated OPEs were much higher during June-August and August-October at MU; June-August, August-October and February-April at UUC; JuneAugust at CAM and HMT; and April-June and August-October at BTU. At the two industrial sites there was more uniformity. Levels were higher (and similar) during February-April and April-June and lower (and quite uniform) during the three other periods at DOID; at KOID levels were much lower during February-April and fairly uniform during the other months (with the highest levels during June-August). In the case of halogenated OPEs, levels were higher during the warmer months for five sites, with highest levels during August October at MU and KOID, during June-August at AGK and CAM, and April-June at BTU. Levels were higher during the colder months, with highest levels during October-December at HMT, DOID, and UUC (with levels during these months nearly similar to the highest values during June-August at (AM).

\subsection{OPEs in soil}

Concentrations (in ng/g dw) of total OPEs in soils are shown in Fig. 6. Total OPEs were in the order BTU $(468 \mathrm{ng} / \mathrm{g})>\mathrm{MU}(379 \mathrm{ng} / \mathrm{g})>$ KOID $(186 \mathrm{ng} / \mathrm{g})>$ UUC $(169 \mathrm{ng} / \mathrm{g})>$ DOID $(149 \mathrm{ng} / \mathrm{g})>$ HMT $(74 \mathrm{ng} / \mathrm{g})$ $>$ AGK $(41 \mathrm{ng} / \mathrm{g})>$ CAM $(37 \mathrm{ng} / \mathrm{g})$. The reasons for the high levels of OPEs at the background site are unclear. However, this site, while removed from the city was at a high elevation. As noted previously, OPEs from the urban and industrial areas of Bursa may be undergoing transport to higher elevations. This, coupled with vehicular traffic in the vicinity from people traveling to Mount Uludag skiing area located farther up the mountain may result in deposition and high levels at this site. Table 3 in SI shows the organic carbon content in each soil sample. Levels of OPEs do not correlate with organic carbon content of soils.

Alkylated OPEs were the dominant type at 5 of the 8 sites (MU, UUC, BTU, KOID and DOID), ranging from $88 \%$ (KOID) to $97 \%$ (MU); 


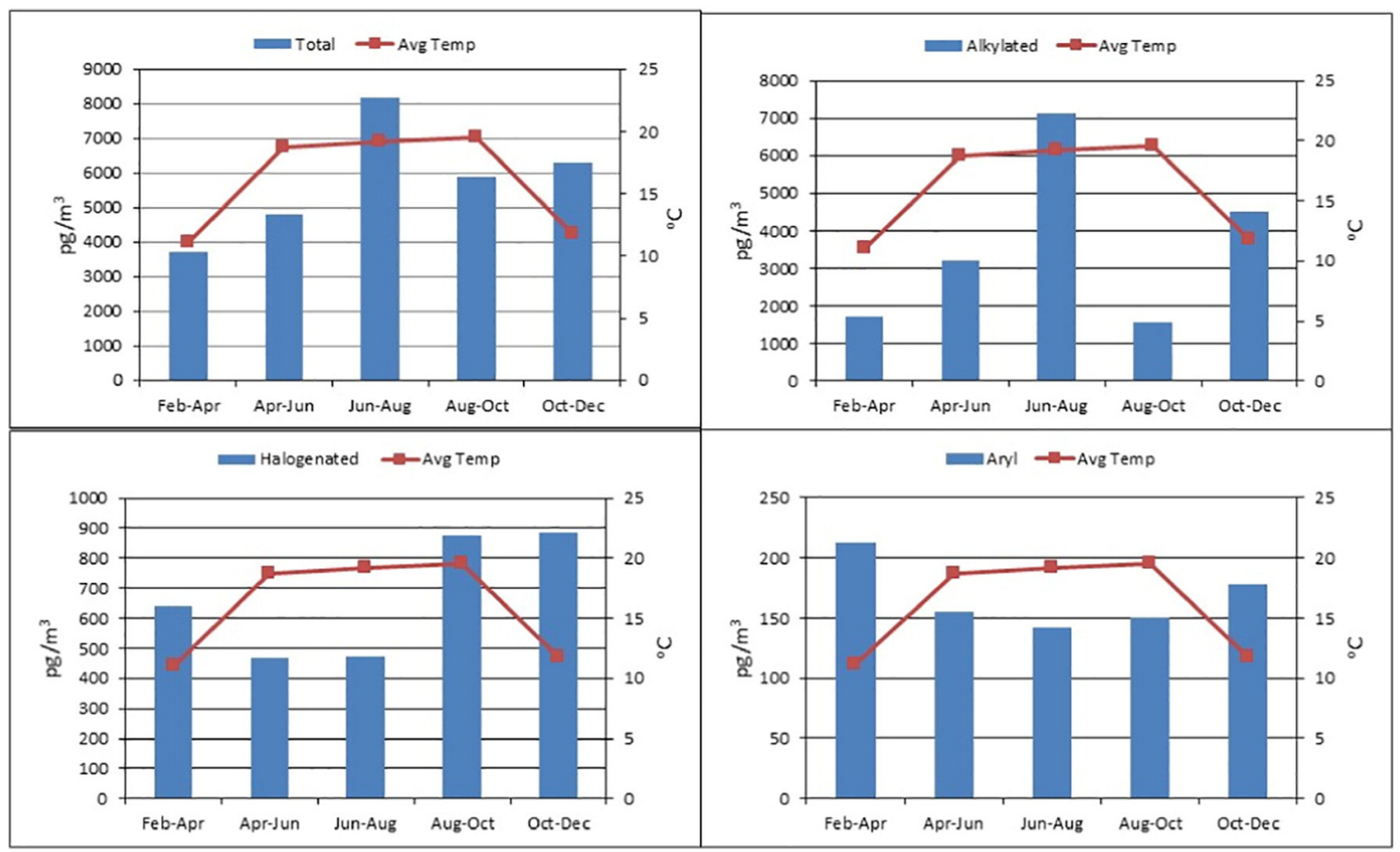

Fig. 4. Comparison of OPEs in air by season.

halogenated OPEs were dominant at 2 sites (87\% at HMT and $89 \%$ at AGK); and at 1 site (CAM) the two types were approximately equal in relative contribution (45\%). It is difficult to explain the difference at these three sites. It may be a reflection of the type of OPEs used in the nearest sources. Halogenated OPEs are generally used to a greater extent as flame retardants compared with alkylated OPEs and the sources nearest these three sites may use these more extensively so their presence in the soils may reflect this. For example, Fig. S4 indicates differences between the two organised industrial areas nearest HMT and CAM (NOID and BOID) compared to the other three (BID, KOID and DOID). In the latter three, the textile industry was the overwhelmingly dominant industry, accounting for over 50\%. In NOID and BOID, however, textiles account for $<50 \%$, and instead automotive parts, machinery, and metals are significant industries and it is possible that halogenated OPEs are used more extensively in these industries. However, an analysis of the exact type of OPEs used in each type of industry is difficult because these can change based on factors such as availability.

OPEs profiles were compared between soil and air in February April (since soils were collected at the beginning of this sampling period). They were similar at 5 sites. At MU, UUC, KOID and DOID alkylated OPEs dominated total levels (with relative contributions being alkylated $>$ halogenated > aryl) and at AGK halogenated OPEs were dominant (with relative contributions being halogenated $>$ alkylated $>$ aryl) in both soil and air. At the two urban sites the profiles in air and soil were different: At BTU, relative contributions were halogenated $>$ aryl $>$ alkylated in air but alkylated $>$ halogenated $>$ aryl in soil while at HMT the profile in air was alkylated $>$ halogenated $>$ aryl while in soil it was halogenated $>$ alkylated $>$ aryl. At CAM relative contributions were in the order alkylated $>$ halogenated $>$ aryl while in soil alkylated and halogenated were virtually identical with aryl OPEs contributing less. Similar profiles in soil and air at some sites may indicate similar or the same sources of OPEs at those sites. However, caution must be exercised in interpreting these results since a more comprehensive study would be needed to study the relationship between air and soil levels.

As with outdoor air levels, there are few reported studies of OPEs in soils. Mihajlovic and Fries (2012) reported values ranging from 5.07-23.48 ng/g dw for TCEP and 5.66-19.82 ng/g dw for TCPP in
Osnabrueck, Germany. Matsukami et al. (2017) reported values for TCEP, TCPP and TPHP in soils from Bui Dau, Vietnam from three environments (median, range): TCEP $-<2 \mathrm{ng} / \mathrm{g} \mathrm{dw}$ in rice raddy soil, $<2 \mathrm{ng} / \mathrm{g} \mathrm{dw}$ in soil from an open burning site and $3.2(3-20) \mathrm{ng} / \mathrm{g} \mathrm{dw}$ in soils from an e-waste workshop site; TCPP $-<4 \mathrm{ng} / \mathrm{g} \mathrm{dw},<4 \mathrm{ng} / \mathrm{g}$ dw and $28(<4-300) \mathrm{ng} / \mathrm{g} \mathrm{dw}$, respectively; and TPHP $-<3(<3-8)$ $\mathrm{ng} / \mathrm{g} \mathrm{dw},<3$ (3-55) ng/g dw and 720 (9.9-4100) ng/g dw, respectively. In comparison, in Bursa TCEP levels in soils ranged from $1.03-2.30 \mathrm{ng} / \mathrm{g} \mathrm{dw}$ (median 1.56), TCPP from 7.11-64.08 ng/g dw (median 17.07), and TPHP from 1.63-2.67 ng/g dw (2.07). Thus, soil levels in Bursa are lower for TCEP and higher for TCPP compared to values in Osnabrueck, Germany. Levels of TCEP in this study were similar to the levels in soils from rice paddies and near open burning sites reported for Vietnam; and they were lower than the levels in soils from an ewaste workshop site in Vietnam. Levels of TCPP were higher than the levels in soils from rice paddies and near open burning sites and lower than levels from the e-waste workshop site in Vietnam. Levels of TPHP were similar the levels from rice paddies and lower than levels in soils from open burning sites and the e-waste workshop site in Vietnam.

\subsection{Correlation between target analytes}

Pearson correlation coefficients were determined to explore the possibility of common sources. The results for air are presented in Table 2. The results indicate weak positive correlations (Pearson coefficients ranging from 0.04 to 0.32 ) between all OPEs. Correlations were all non-significant $(p>0.05)$ except for that between TPHP and TBOEP ( $p$ $<0.05$ ). These results suggest that the OPEs measured in air have some common sources, but these are not necessarily the only or dominant sources in most cases. The weak positive correlations may also be due to differences in environmental fates (e.g. differences in rates of degradation and transport properties). The OPEs have a wide range of character travel distances in air, ranging from $41 \mathrm{~km}$ for TBOEP and $2739 \mathrm{~km}$ for T2iPPP (Sühring et al., 2016), the lack of correlations between OPE compounds may indicate a mixture of local, regional and long-range transport sources.

Pearson correlation coefficients for soils are shown in Table 3. Results indicate positive correlations ranging from weak $(r=0.01)$ to 
a

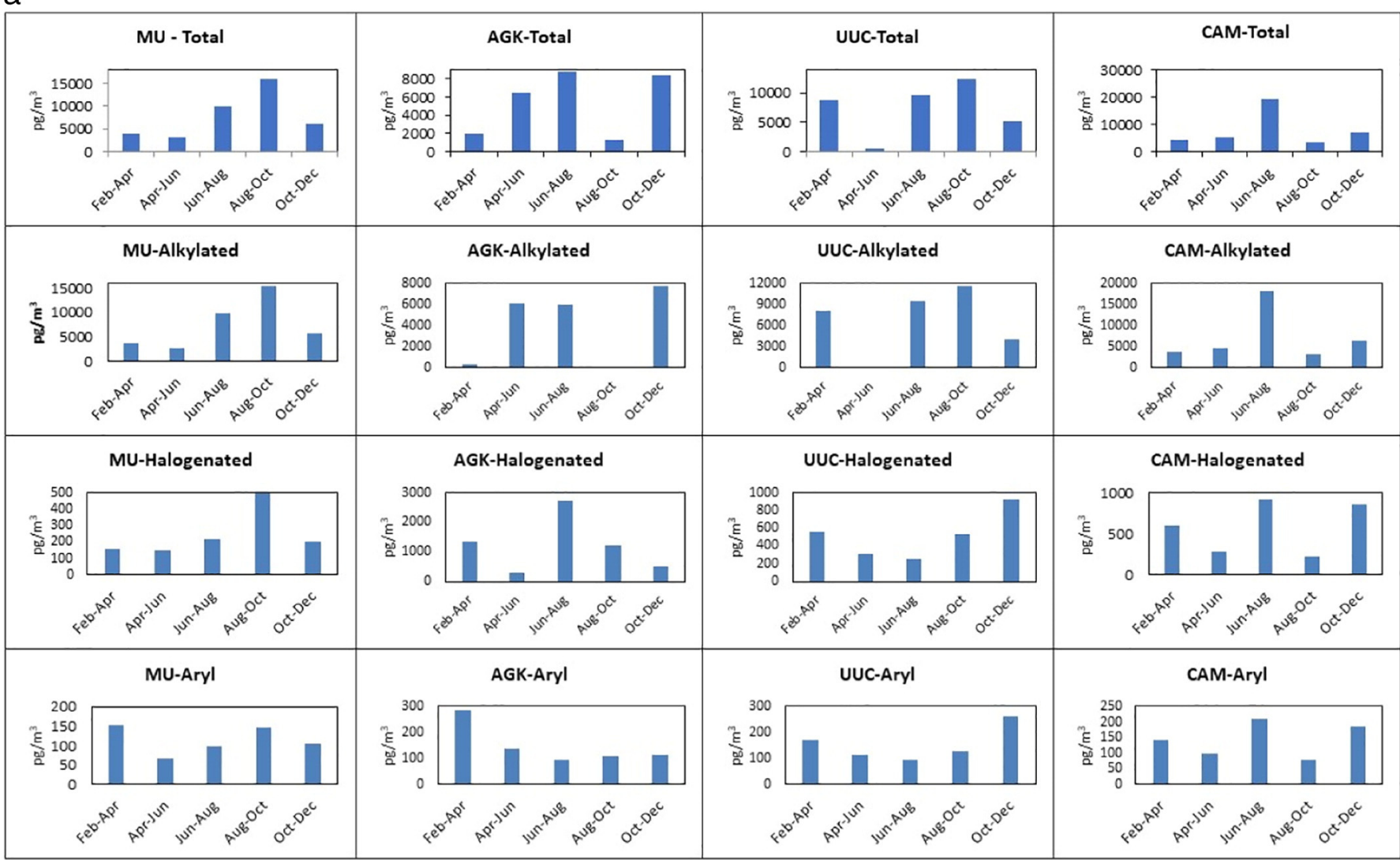

b

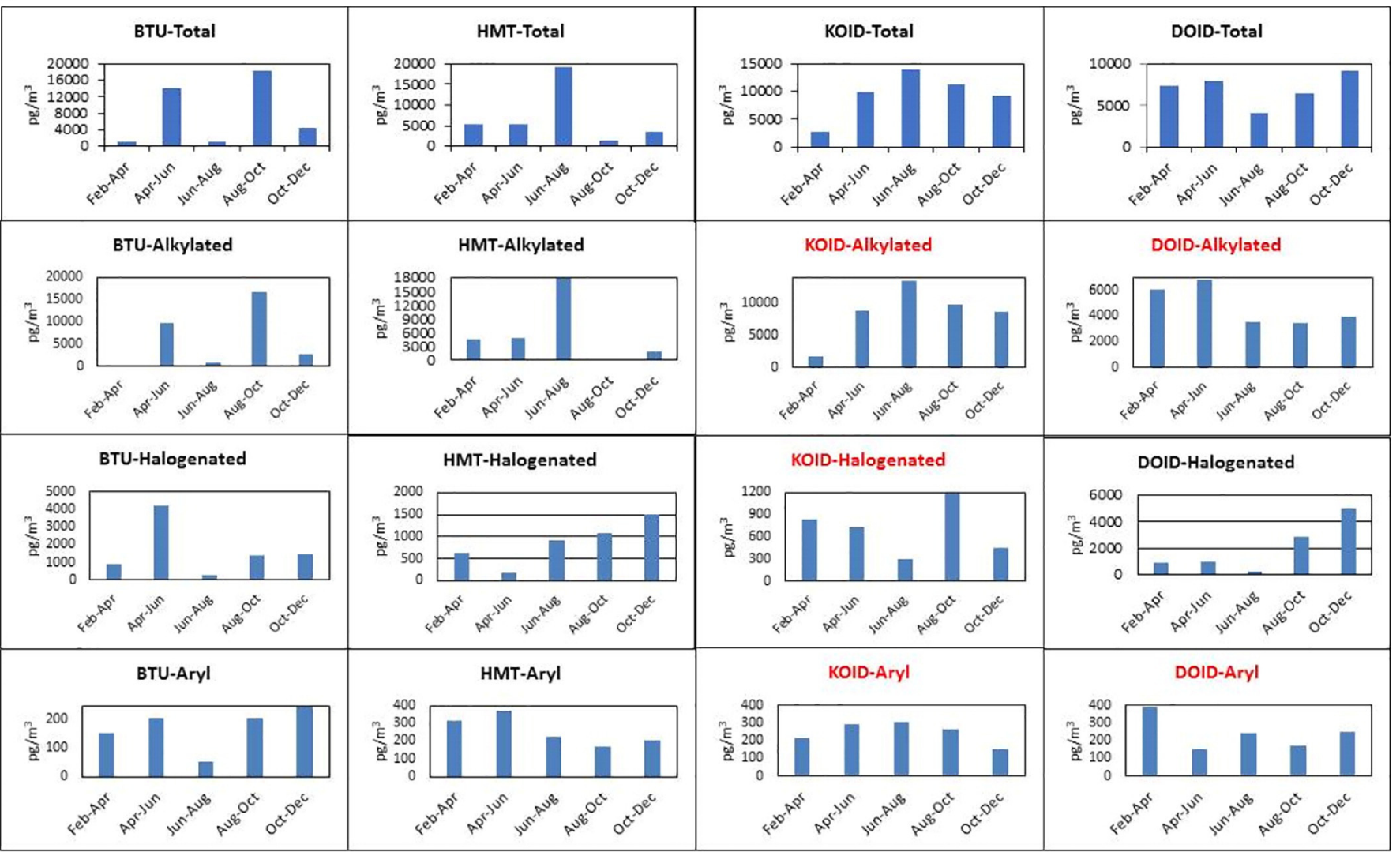

Fig. 5. a,b. Seasonal variation of total OPEs in air at each site. 


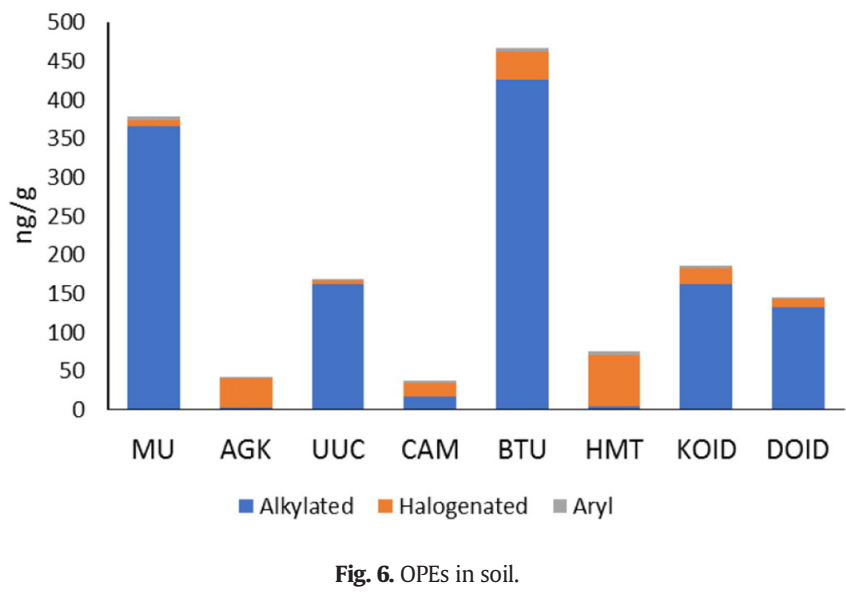

strong $(r=0.87)$ for all pairs of OPEs tested. Correlations were moderately strong ( $r=0.32$ to $r=0.61$ ) between TCEP and TPHP, TBOEP, and T2IPPP; TCPP and TPHP, TBOEP and T2IPPP; and T2IPPP and TBOEP. The correlation was strong $(r=0.87)$ between TPHP and T2IPPP. Only in the case of TPHP and T2IPPP (the aryl OPEs) was the correlation significant $(p<0.05)$. The results suggest that overall, compared with air, the influence of common sources was more important for OPEs in soil.

\section{Conclusions}

The results of this study indicate ongoing emission of OPEs into ambient air in and around the city of Bursa, Turkey. Levels of OPEs in air measured in this study were generally similar or higher than concentrations of PBDEs in ambient air in different regions of the world, including the UK, Europe, the U.S., Asia and Canada. Compared to levels of PBDEs in air reported for Turkey, the levels of OPEs measured in this study are much higher. This suggests that the use of OPEs as replacements for PBDEs has been significant in Turkey. Levels and profiles in this study indicate that OPEs are undergoing regional transport, including to background areas as indicated by the fact that concentrations in air and soils in the background site were not the lowest. The results indicate that further studies are needed to examine the cycling of OPEs in the environment of Turkey.

\section{Acknowledgements}

We thank Scientific and Technological Research Council of Turkey (TUBITAK) for financial support. Dr. Henry Alegria was financially supported by TUBITAK under the support programme "TUBITAK 2221Fellowships for Visiting Scientists and Scientists on Sabbatical Leave" (grant number 21514107-221.01-8290) during his visit to laboratories of Bursa Technical University in 2014. Elif Gungormus received her fellowship from TUBITAK under grant number 112 Y315.

\section{Appendix A. Supplementary data}

Supplementary data to this article can be found online at https://doi. org/10.1016/j.scitotenv.2017.12.307.

\section{Table 3}

Pearson correlation coefficients for measured OPEs in soil.

\begin{tabular}{lllllll}
\hline & TCEP & TCPP & TPHP & TBOEP & TEHP & T2IPPP \\
\hline TCEP & - & 0.06 & 0.61 & 0.56 & 0.07 & 0.59 \\
TCPP & 0.06 & - & 0.32 & 0.32 & 0.01 & 0.49 \\
TPHP & 0.61 & 0.32 & - & 0.05 & 0.07 & $\mathbf{0 . 8 7}$ \\
TBOEP & 0.56 & 0.32 & 0.05 & - & 0.21 & 0.45 \\
TEHP & 0.07 & 0.01 & 0.07 & 0.21 & - & 0.03 \\
T2IPPP & 0.59 & 0.49 & $\mathbf{0 . 8 7}$ & 0.45 & 0.03 & - \\
\hline
\end{tabular}

Bold, italicized values indicate that the correlation was statistically significant $(p<0.05)$.

\section{References}

Abdallah, M.A.-E., Covaci, A., 2014. Organophosphate flame retardants in indoor dust from Egypt: implications for human exposure. Environ. Sci. Technol. 48, 4782-4789.

Abdollahi, A., Eng, A., Jantunen, L.M., Ahrens, L., Shoeib, M., Parnis, J.M., Harner, T., 2017. Characterization of polyurethane foam (PUF) and sorbent impregnated PUF (SIP) disk passive air samplers for measuring organophopshate flame retardants. Chemosphere 167, 212-219.

ASTM, 2000a. D2974-00, Standard Test Methods for Moisture, Ash, and Organic Matter of Peat and Other Organic Soils, Test Method A.

ASTM, 2000b. D2974-00, Standard Test Methods for Moisture, Ash, and Organic Matter of Peat and Other Organic Soils, Test Method C.

Bergman, A., Ryden, A., Law, R.J., de Boer, J., Covaci, A., Alaee, M., Birnbaum, L., Petreas, M., Ose, M., Sakai, S., Van den Eede, N., van der Veen, I., 2012. A novel abbreviation standard for organobromine, organochlorine and organophosphorus flame retardants and some characteristics of the chemicals. Environ. Int. 49, 57-82.

Birgul, A., Kurt-Karakus, P.B., Alegria, H., Gungormus, E., Celik, H., Cicek, T., Can-Guven, E., 2017. Polyurethane foam (PUF) disk passive samplers derived polychlorinated biphenyls (PCBs) concentrations in the ambient air of Bursa-Turkey: spatial and temporal variations and health risk assessment. Chemosphere 168, 1345-1355.

Carignan, C.C., McClean, M.D., Cooper, E.M., Watkins, D.J., Fraser, A.J., Heiger-Bernays, W., Stapleton, H.M., Webster, T.F., 2013. Predictors of tris(1,3-dichloro-2-propyl) phosphate metabolite in the urine of office workers. Environ. Int. 55, 56-61.

Cequier, E., Ionas, A.C., Covaci, A., Marcé, R.M., Becher, G., Thomsen, C., 2014. Occurrence of a broad range of legacy and emerging flame retardants in indoor environments in Norway. Environ. Sci. Technol. 48, 6827-6835.

China Market Research Reports, Global and China Flame Retardant Industry Report, 2014 2016. http://www.chinamarketresearchreports.com/114859.html (Access on 15 December 2016).

Gouin, T., Harner, T., Blanchard, P., Mackay, D., 2005. Passive and active samplers as complementary methods for investigating persistent organic pollutants in the Great Lakes Basin. Environ. Sci. Technol. 39, 9115-9122.

Greaves, A.K., Letcher, R.J., 2017. A review of organophosphate esters in the environment from biological effects to distribution and fate. Bull. Environ. Contam. Toxicol. 98, 2-7.

Greaves, A., Letcher, R., Chen, D., McGoldrick, D.J., Gauthier, L.T., Backus, S.M., 2016. Retrospective analysis of organophosphate flame retardants in herring gull eggs and relation to the aquatic food web in the Laurentian Great Lakes of North America. Environ. Res. 150, 255-263.

Gul, E., Cevik, B., 2015. An Investigation on Development Level of Provinces in Turkey Based on 2013 Economic and Social Devlopment Indexes. Economic Researches Department, İsbank of Turkey (available at). https://ekonomi.isbank.com.tr/UserFiles/ pdf/ar_07_2015.pdf (accessed on 27 January 2017, (in Turkish))

Guo, J., Venier, M., Salamova, A., Hites, R.A., 2017. Bioaccumulation of Dechloranes, organophosphate esters, and other flame retardants in Great Lakes fish. Sci. Total Environ. $583,1-9$.

Hallanger, I.G., Sagerup, K., Evenset, A., Kovacs, K.M., Leonards, P., Fuglei, E., Routti, H., Aars, J., Strøm, H., Lydersen, C., Gabrielsen, G.W., 2015. Organophosphorous flame retardants in biota from Svalbard, Norway. Mar. Pollut. Bull. 101, 442-447.

Harner, T., 2016. v1 3 Template for calculating PUF and SIP disk sample air volumes March 11 2016. (available at). https://www.researchgate.net/publication/298350415_2016_ v1_3_Template_for_calculating_PUF_and_SIP_disk_sample_air_volumes_March_11_ 2016 (accessed on 27 January 2017).

Harner, T., Shoeib, M., Diamond, M.L., Stern, G., Rosenberg, B., 2004. Using passive air samplers to assess urban-rural trends for persistent organic pollutants. 1. Polychlorinated biphenyls and organochlorine pesticides. Environ. Sci. Technol. 38, 4474-4483.

Hoffman, K., Garantziotis, S., Birnbaum, L.S., Stapleton, H.M., 2015. Monitoring indoor exposure to organophosphate flame retardants: hand wipes and house dust. Environ. Health Perspect. 2015 (123), 160-165.

Hoffman, K., Butt, C.M., Webster, T.F., Preston, E.V., Hammel, S.C., Makey, C., Lorenzo, A.M., Cooper, E.M., Carignan, C., Meeker, J.D., Hauser, R., Soubry, A., Murphy, S.K., Price, T.M. Hoyo, C., Mendelsohn, E., Congleton, J., Daniels, J.L., Stapleton, H.M., 2017. Temporal trends in exposure to organophosphate flame retardants in the United States. Environ. Sci. Technol. Lett. 4:112e118. https://doi.org/10.1021/acs.estlett.6b00475.

Iqbal, M., Syed, J.H., Katsoyiannis, A., Malik, R.N., Farooqi, A., Butt, A., Li, J., Zhang, G., Cincinelli, A., Jones, K.C., 2017. Legacy and emerging flame retardants (FRs) in the freshwater ecosystem: a review. Environ. Res. 152, 26-42.

Jaward, F.M., Farrar, N.J., Harner, T., Sweetman, A.J., Jones, K.C., 2004. Passive air sampling of PCBs, PBDEs and organochlorine pesticides across Europe. Environ. Sci. Technol. 38, 34-41.

Kim, J.-W.W., Isobe, T., Muto, M., Tue, N.M., Katsura, K., Malarvannan, G., Sudaryanto, A Chang, K.-H.H., Prudente, M., Viet, P.H., Takahashi, S., Tanabe, S., 2014. Organophosphorus flame retardants (PFRs) in human breast milk from several Asian countries. Chemosphere 116:91e97. https://doi.org/10.1016/j.chemosphere.2014.02.033.

Kurt-Karakus, P.B., Jantunen, L.M., Topcu, A., Tepe, S., 2014. Selected organophosphate flame retardants in Turkish indoor dust. Organohalogen Compd. 76, 649-652.

Kurt-Karakus, P.B., Jantunen, L.M., Topcu, A., Yalcin, M., Alegria, H., Turgut, C., Jones, K.C., 2015. Brominated and phosphate flame retardants in indoor dust from Istanbul: occurrence and human exposure assessment. Organohalogen Compd. 77, 43-46.

Kurt-Karakus, P., Alegria, H., Jantunen, L., Topcu, A., Jones, K., Torgut, C., 2017. PBDEs and novel brominated flame retardants (NBFRs) in indoor dust and air of Istanbul Turkey. Atmos. Pollut. Res. 8, 5,801-815.

Laniewski, K., Boren, H., Grimvall, A., 1998. Identification of volatile and extractable chloro-organics in rain and snow. Environ. Sci. Technol. 32, 3935-3940.

LeNoir, J.S., McConnell, L.L., Fellers, G.M., Cahill, T.M., Seiber, J.N., 1999. Summertime transport of current-use pesticides from California's Central Valley to the Sierra Nevada Mountain Range, USA. Environ. Technol Chem. 18, 2715-2722. 
Luo, P., Bao, L.-J., Guo, Y., Li, S.-M., Zeng, E.Y., 2016. Size-dependent atmospheric deposition and inhalation exposure of particle-bound organophosphate flame retardants. J. Hazard. Mater. 301, 504-511.

Marklund, A., Andersson, B., Haglund, P., 2003. Screening of organophosphorus compounds and their distribution in various indoor environments. Chemosphere 53 , 1137-1146.

Marklund, A., Andersson, B., Haglund, P., 2005. Traffic as a source of organophosphorus flame retardants and plasticizers in snow. Environ. Sci. Technol. 39, 3555-3562.

Matsukami, H., Suzuki, G., Someya, M., Uchida, N., Nguyen, M.T., Le, H.T., Pham, H.V., Takahashi, S., Tanabe, S., Takigami, H., 2017. Concentrations of polybrominated diphenyl ethers and alternative flame retardants in surface soils and river sediments from an electronic waste-proessing in Northern Vietnam, 2014-2014. Chemosphere $167,291-299$

McPherson, A., Thorpe, B., Blake, A., 2004. Brominated flame retardants in dust on computers: the case for safer chemicals and better computer design. Clean Production Action Report http://svtc.org/wp-content/uploads/bfr_report_pages1-43.pdf (accessed on Jan 31, 2017).

Meijers, A.P., van der Leer, R.C., 1976. The occurrence of organic micropollutants in the river Rhine and the river Maas in 1974. Water Res. 10, 597-604.

Mihajlovic, I., Fries, E., 2012. Atmospheric deposition of chlorinated organophosphate flame retardants (OFR) onto soils. Atmos. Environ. 56, 177-183.

Möller, A., Xie, Z., Caba, A., Sturm, R., Ebinghaus, R., 2011. Organophosphorus flame retardants and plasticizers in the atmosphere of the North Sea. Environ. Pollut. 159, 3660-3665.

Möller, A., Sturm, R., Xie, Z., Cai, M., He, J., Ebinghaus, R., 2012. Organophosphorus flame retardants and plasticizers in airborne particles over the Northern Pacific and Indian Ocean toward the polar regions: evidence for global occurrence. Environ. Sci. Technol. 46, 3127-3134.

Motelay-Massei, A., Harner, T., Shoeib, M., Diamond, M., Stern, G., Rosenberg, B., 2005. Using passive air samplers to assess urban-rural trends for persistent organic pollutants and polycyclic aromatic hydrocarbons. 2. Seasonal trends for PAHs, PCBs and organochlorine pesticides. Environ. Sci. Technol. 39, 5763-5773.

Muir, D.C.G., Grift, N.P., Blouw, A.P., Lockhart, W.L., 1980. Environmental dynamics of phosphate esters. I. Uptake and bioaccumulation of triphenyl phosphate by rainbow trout. Chemosphere 9, 525-532.

NIP, 2014. National Implementation Plan on POPs (Draft Report). Ministry of Environment and Urbanization https://www.csb.gov.tr/db/cygm/editordosya/UUP_ Taslak.pdf (accessed on March 15, 2015 (in Turkish)).

Ohura, T., Amagai, T., Senga, Y., Fusaya, M., 2006. Organic air pollutants inside and outside residences in Shimizu, Japan: levels, sources and risks. Sci. Total Environ. 366, 485-499.

Parnis, J.M., Eng, A., Mackay, D., Harner, T., 2016. Characterizing PUF disk passive air samplers for alkyl-substituted PAHs: measured and modelled PUF-AIR partition coefficients with COSMO-RS. Chemosphere 145, 360-364.

Poma, G., Glynni, A., Malarvannan, G., Covaci, Açi, Darnerud, P.O., 2017. Dietary intake of phosphorus flame retardants (PFRs) using Swedish food market basket estimations. Food Chem. Toxicol. 100, 1-7.

Pozo, K., Harner, T., Shoeib, M., Urrutia, R., Barra, R., Parra, O., Focardi, S., 2004. Passive sample derived air concentrations of persistent organic pollutants on a north-south transect in Chile. Environ. Sci. Technol. 38, 6529-6537.

Reemtsma, T., Quintane, J.B., Rodil, R., Garcia-Lopez, M., Rodriguez, I., 2008. Organophosphorus flame retardands and plasticizers in air and water I. Occurrence and fate. Trends Anal. Chem. 27, 727-737.
Regnery, J., Püttmann, W., 2009. Organophosphorus flame retardants and plasticizers in rain and snow from Middle Germany. CleanRooms 37, 334-342.

Regnery, J., Püttmann, W., 2010. Seasonal fluctuations of organophosphate concentrations in precipitation and storm water runoff. Chemosphere 78, 958-964.

Salamova, A., Ma, Y., Venier, M., Hites, R., 2014a. High levels of organophosphate flame retardants in the Great Lakes atmosphere. Environ. Sci. Technol. Lett. 1, 8-14.

Salamova, A., Hermanson, M.H., Hites, R.A., 2014b. Organophosphate and halogenated flame retardants in atmospheric particles from a European Arctic site. Environ. Sci. Technol. 48, 6133-6140.

Sheldon, L.S., Hites, R.A., 1978. Organic compounds in the Delaware River. Environ. Sci. Technol. 12, 1188-1194.

Shoeib, M., Harner, T., 2002. Characterization and comparison of three passive air samplers for persistent organic pollutants. Environ. Sci. Technol. 36, 4142-4151.

Shunthirasingham, C., Gouin, T., Lei, Y.D., Ruepert, C., Castillo, L.E., Wania, F., 2011. Current-use pesticide transport to Costa Rica's high-altitude tropical rain forest. Environ. Technol. Chem. 30, 2709-2717.

Sühring, R., Diamond, M.L., Scheringer, M., Wong, F., Pucko, M., Stern, G., Burt, A., Hung, H., Fellin, P., Li, H., Jantunen, L.M., 2016. Organophosphate esters in Canadian Arctic air: occurrence, levels and trends. Environ. Sci. Technol. 50, 7409-7415.

Sundkvist, A.M., Olofsson, U., Haglund, P., 2010. Organophosphorus flame retardants and plasticizers in marine and fresh water biota and in human milk. J. Environ. Monit. 12, 943-951.

Tachikawa, R., Wakimoto, T., Okada, K., 1975. Water pollution by organic phosphate ester plasticizers and flame retardants. JSWP Symposium Series. 9. Japan Society on Water Pollution Research, Tokyo, pp. 7-12.

Tajima, S., Araki, A., Kawai, T., Tsuboi, T., Bamai, Y.A., Yoshioka, E., Kanazawa, A., Cong, S. Kishi, R., 2014. Detection and intake assessment of organophosphate flame retardants in house dust in Japanese dwellings. Sci. Total Environ. 478, 190-199.

TUIK, 2017. Turkish Statistics Institute, Address-Based Population Registration Results. https://biruni.tuik.gov.tr/medas/?kn=95\&locale $=\operatorname{tr}$ (accessed on 15 January 2017).

Van den Eede, N., Dirtu, A.C., Ali, N., Neels, H., Covaci, A., 2012. Multi-residue method for the determination of brominated and organophosphate flame retardants in indoor dust. Talanta 89, 292-300.

Van den Eede, N., Heffernan, A.L., Aylward, L.L., Hobson, P., Neels, H., Mueller, J.F., Covaci, A., 2015. Age as a determinant of phosphate flame retardant exposure of the Australian population and identification of novel urinary PFR metabolites. Environ. Int. 74, 1-8.

Van der Veen, I., de Boer, J., 2012. Phosphorus flame retardants: properties, production, environmental occurrence, toxicity and analysis. Chemosphere 88, 1119-1153.

Wong, F., Alegria, H.A., Bidleman, T.F., 2009. Passive air sampling of organochlorine pesticides in Mexico. Environ. Sci. Technol. 43, 704-710.

Wong, F., Alegria, H.A., Bidleman, T.F., 2010. Organochlorine pesticides in soils of Mexico and the potential for soil-air exchange. Environ. Pollut. 158, 749-755.

Yilmaz Civan, M., 2016. Levels of halogenated persistent organic pollutants measured in indoor environment of a University (Üniversite Iç Ortaminda Ölçülen Halojenli Kalici Organik Kirleticilerin Seviyeleri). (In Turkish Language). Gazi Üniversitesi Fen Bilimleri Dergisi Part:C, Tasarım Ve Teknoloji GU J Sci Part:C 4 (4), 321-329 (2016).

Zhao, F., Wan, Y., Zhao, H., Hu, W., Mu, D., Webster, T.F., Hu, J., 2016. Levels of blood organophosphorus flame retardants and association with changes in human sphingolipid homeostasis. Environ. Sci. Technol. https://doi.org/10.1021/acs.est.6b02474 acs.est.6b02474. 